\title{
CONTEMPORANEIDADE E VIOLÊNCIA: OS DESLOCAMENTOS E INCERTEZAS NO MUNDO JURÍDICO POLITICO CONTEMPORÂNEO
}

CONTEMPORANEITY AND VIOLENCE: DISPLACEMENTS AND UNCERTAINTS IN THE CONTEMPORARY POLITICAL LEGAL WORLD

\section{Ruth Maria Chittó Gauer \\ PUC-RS}

\begin{abstract}
Resumo
O surgimento de novas escolas no século XIX - como a psicologia e a sociologia - que influenciaram sobremaneira os estudos políticos, desembocarão na crise do século XX, com sua relação com o conceito de devir. A mudança de paradigmas acarreta a mutação do sujeito e da temporalidade, conduzindo à epistemologia das incertezas, característica do tempo presente.
\end{abstract}

Palavras-chaves

Violência. Incertezas. História das Ideias. Contemporaneidade.

\section{Abstract}

The emergence of new schools in the nineteenth century - such as psychology and sociology - which greatly influenced political studies, will lead to the crisis of the twentieth century, with its relation to the concept of becoming. The change of paradigms entails the mutation of subject and temporality, leading to the pistemology of uncertainties characteristic of the present time.

Keywords

Violence. Uncertainty. History of Ideas. Contemporaneity

\section{Introdução}

1 Coordenadora do Programa de Pós-graduação em Ciências Criminais da PUC-RS. Doutora em História e Teoria das Ideias pela Universidade de Coimbra. 
O pensamento político e social do século XX apresentam-se de duas maneiras: morto e vivo. A filosofia política "morta" é aquela que está ligada à teoria acadêmica, que reflete o declínio da democracia liberal; por outro lado o debate político na praça, a política ideológica on partidária encontra-se muito viva. Weber ressaltava que a ciência - no caso a ciência política- deveria ajudar os homens a encontrar soluções racionais para os problemas sociais; os valores e os juízos de valor pertencem a fé e não aos conhecimentos Karl Mannheim: assim como Weber ${ }^{2}$ propõem a historização da teoria política. Os Positivistas, por seu turno, criticavam a filosofia política tradicional partindo de bases lógicas e linguísticas, excluindo-a como metafísica e colocavam a ideia de limite com base na premissa que o conhecimento político era socialmente determinado. As ideologias políticas floresciam nas lutas e dificuldades.

No centro da questão, coloca-se a batalha entre liberalismo, comunismo e fascismo. Em Weber $^{3}$ há a racionalização crescente da vida e do pensamento na Europa Moderna. Para o autor, o grande perigo do discurso político moderno seria a direção de forças irracionais, a condução pelo irracionalismo, que ameaçava destruir a estrutura da vida social e política racionalizada. Nos finais do século XIX o irracionalismo estava a ganhar em movimento e prestígio. Este irracionalismo apresenta-se no pensamento político em dois níveis: na conduta não lógica no campo social e em apelos diretos, como no fascismo, a intuição e ao mito como guias para a ação social e na exclusão da razão critica nos indivíduos e nas massas. Tais eixos são geradores de violência e tencionam o pensamento político da contemporaneidade.

\section{Política e engenharia social: violência e crise no século XX.}

2 WEBER, Max. O cientista e o político. 3 ed. Lisboa Presença, 1979, passim.

3 WEBER, Max. O cientista e o politico. Op. Cit. 
Karl Popper desenvolve o pensamento sobre a engenharia social "fragmentária" em uma 'sociedade aberta". A velha imagem do mundo como um mecanismo funcionando por impulsos ou por causas abstratas que estão todas no passado - o passado empurrando-nos e levando-nos para o futuro, o passado que passou - já não se adapta ao nosso mundo indeterminista de propensões". Popper ${ }^{4}$ na realidade, assume aqui o legado de toda uma anterior tradição crítica ao raciocínio probabilístico de cunho determinista. Uma tradição alimentada, por vezes, ironicamente, a partir dos próprios avanços do conhecimento. Através do pensamento deste intelectual Baumer quer deixar claro o irracionalismo dentro da doutrina. Popper defendia o liberalismo, porém do ponto de vista do método científico. O Devir leva a uma análise do quadro, muito completo, da discussão do pensamento social do século XX, a análise da Comunidade Econômica Europeia, pode ser vista como a comunidade que poderá vir a tornar-se a mais importante ideia europeia de reorganização social do século.

A "crise" da história começara bem antes, mas atingiu grandes proporções no século XX, especialmente depois de 1914. As antigas filosofias revivem e florescem, porém modificadas. Baumer afirma que apesar de Collingwood ser um historicista, nunca historicizou completamente a metafísica. O ser, objeto do pensamento metafísico, constituía a realidade de que, a história, a ciência, a arte e a religião eram aparências. No entanto, na maior parte, a "razão" na história, a vitória da persuasão sobre a força, o poder das grandes ideias, baseadas no sentimento, para modificarem as épocas e melhorarem a condição humana estavam presentes nestas ideias. A novidade na filosofia da história, segundo Baumer, não era o otimismo, quer fosse o antigo ou o novo, mas, pelo contrário, o pessimismo, ou ceticismo que, antes de qualquer coisa, questionava a validade do próprio conhecimento histórico. Estes debates

${ }^{4}$ POPPER, Karl, R. Um Mundo De Propensões. Lisboa: Fragmentos, 1991. P. 33. 
se deram principalmente entre as décadas de 1920 e 1930. Embora centrado na Alemanha, o debate percorreu a Europa e espalhou-se pelos Estados Unidos. As conclusões sobre o conhecimento histórico variavam de um ceticismo completo ao moderado. Segundo Weber, embora cético com reação a normas,

pensava que pelo menos o conhecimento objetivo do mundo social podia ser atingido por meio de um método racional. Por outro lado, sobretudo na Alemanha, evidenciava-se um ceticismo epistemológico ao extremo. Para um número cada vez maior de pessoas, a história, tal como o homem, tornou-se problemática. Além de historiadores e filósofos profissionais, muitos outros especularam sobre o significado da história, chegando a conclusões bastante novas e muitas vezes pessimistas. Popper, ao apresentar as conferências de 1988, em Brighton, e de 1989, na London School of Economies, demonstrou uma grande preocupação perante a permanência de uma visão científica embasada na probabilidade, criticando duramente o que considerava ser a expressão de uma visão determinista. Para o autor, a teoria segundo a qual as nossas ações são determinadas por certas causas e que essas são determinadas por outras, parece ser, ela própria, motivada pelo desejo de estabelecer a ideologia do determinismo nos assuntos humanos. Um desejo cuja manutenção não encontra, na sua ótica, qualquer justificação no mundo presente, pelo que afirma:

"A velha imagem do mundo como um mecanismo funcionando por impulsos ou por causas abstratas que estão todas no passado - o passado empurrando-nos e levando-nos para o futuro, o passado que passou - já não se adapta ao nosso mundo indeterminista de propensões. $\mathrm{Na}$ realidade, Popper assume aqui o legado de toda uma anterior tradição crítica ao raciocínio probabilístico de cunho determinista. 
Uma tradição alimentada, por vezes, ironicamente, a partir dos próprios avanços do conhecimento". 5

Exemplo, talvez o mais emblemático, de como se foi impondo a convicção de um défice de previsibilidade dos caminhos da ciência, encontra-se no papel desempenhado pelas teorias de Einstein. Se o cientista

"descobriu a equação $e=M C^{2}$ (uma das mais conhecidas equações da física moderna) não foi, evidentemente, com a intenção de dar à técnica humana os meios de fabricar armas de destruição. (...). A utilização da energia nuclear ou termonuclear já estava contida nessa equação, mas nunca foi a sua motivação" ${ }^{6}$.

Mas, fundamentalmente, quando Einstein constatando a impossibilidade do observador estabelecer a ordem temporal dos acontecimentos no espaço - não havendo na natureza velocidade superior à luz, para medir a velocidade faz-se necessário conhecer a simultaneidade dos acontecimentos — , põe em dúvida o caráter absoluto do tempo e do espaço, ele rompe com a cosmovisão moderna. Einstein demonstra que a simultaneidade dos acontecimentos distantes não pode ser verificada, tão só definida, e, dada a arbitrariedade das medições, a hipótese de contradição dos resultados é forçosamente incorporada. Sob esse aspecto, uma nova concepção de conhecimento afeta a visão do tempo que lhe está associada. O tempo no mundo, ao tornar-se incerto, torna-se, por consequência, diferente do tempo das ciências modernas, onde era definido pela possibilidade de definir leis universais e eternas da natureza. Portanto, a produção de conhecimento, privado da verdade universal, somente pode ser apoiada mediante uma postura de conhecimento provisório. À idealizada objetividade do conhecimento

5POPPER, Karl. Op cit. P.33.

${ }^{6}$ PECKER, Jean-Claude.. IN: Ideias Contemporâneas (Entrevistas do Le Monde). São Paulo: Ática, 1984. P. 45. 
científico sobrepõe-se o pluralismo de verdades, à necessidade de regras do método junta-se a necessidade de uma mediação jurídico-político. No entanto não podemos esquecer que a questão da democracia que se reporta às questões como liberdade e igualdade, temas herdados do jusnaturalismo e do contratualismo, foi abordado por Tocqueville ${ }^{7}$ de forma emblemática quando afirmava que "o preço da liberdade é a eterna vigilância”.

\section{O sujeito e a crise}

Entretanto, reportando-nos a uma preocupação de sempre da história do pensamento Ocidental - a relação entre o Ser e o sentido, entre o sujeito e o objeto, entre o homem e a natureza - é possível verificar que, desde Descartes, esse diálogo tensional como que derivou a favor de um peso excessivo do pólo do sujeito. Octavio $\mathrm{Paz}^{8}$ afirma: mesmo os que apelaram para a filosofia como forma de realizar uma leitura do mundo terão encontrado sobretudo um monólogo do sujeito, ao ponto de, na opinião do autor, o mundo ter emudecido: o diálogo da filosofia com o mundo convertera-se no monólogo interminável do sujeito. Este crescimento do sujeito às expensas do mundo (que não se limita à corrente idealista propriamente dita, na medida em que a natureza histórica de Marx e a natureza "domesticada" da ciência experimental e da tecnologia ostentam a mesma marca) conhece, porém, um momento de particular inversão tendêncial. Lévi-Strauss rompe brutalmente com essa situação e inverte os termos: agora é a natureza que fala consigo mesma, através do homem e sem que este se dê conta. Não é o homem, mas o mundo, que não consegue sair de si mesmo. Para o autor

7 WEFFORD, Francisco. (Organizador). Os clássicos da politica. São Paulo, Àtica, 1991. P. 157.

8 PAZ, Octavio. Claude Lévi-Strauss, on o Novo Festim de Esopo. São Paulo: Perspectiva, 1977, p. 97. 
"o homem em si nem sequer é inacessível: é uma ilusão, a cifra momentânea de uma operação. Um signo de troca, como os bens, as palavras e as mulheres" ".

Por meio de reduções sucessivas e rigorosas, o autor percorre o caminho da filosofia moderna em sentido inverso e para chegar a conclusões simetricamente opostas: reduz, por exemplo, a pluralidade das sociedades e histórias a uma dicotomia que as engloba e as dissolve (pensamento selvagem e pensamento domesticado); posiciona-se diante das questões natureza/cultura como oposições, ao mesmo tempo em que descreve uma identidade entre ambas como sendo o produto da cultura; refere-se aos mitos, às instituições, à linguagem, como não sendo essencialmente distintos dos produtos naturais nem obedecendo a leis diferentes das que regem as células, entendidas, em tudo, como suas homólogas. Tudo para ele é matéria que se transforma. A cultura seria uma metáfora do espírito humano. As perguntas feitas ${ }^{10}$ são fundamentais, mas esse espírito humano, como vê? Que tipo de olhar é solicitado pela própria cultura?

Falar em deslocamentos de perspectiva no âmbito do paradigma de conhecimento da modernidade implica, igualmente, que seja tida em conta a questão do olhar. Aceitando-se como sólida vocação desse paradigma a associação entre "realidade" e verdade, ou entre busca do visível e vontade de verdade, compreende-se que qualquer desvio da problemática em direção a uma recolocação do obscuro e da opacidade na linha de prioridades do conhecimento seja, por si só, fator de perturbação sobre o entendimento canônico daquela vontade de verdade. E, de fato, como aceitar sem perturbação que a verdade possa, de alguma maneira, produzir opacidade? Foucault, ao analisar o que considera serem os grandes temas privilegiados pelos relatos legitimadores do presente,

${ }^{9}$ LÉVI-STRAUSS, Claude. O Pensamento Selvagem. Campinas: Papirus, 1989.

${ }^{10}$ LÉVI-STRAUSS, Claude. Op. Cit. 
assinala que não são as condições políticas e econômicas da existência que constituem, em si mesmas, obstáculos a desmontar e a descodifica em ordem à busca da verdade, mas sim

"certos domínios de saber (...) em que se formam o sujeito e as relações com a verdade". Donde refere: "só se desembaraçando desses grandes temas do sujeito, do conhecimento, ao mesmo tempo originário e absoluto, utilizando eventualmente o modelo nietzscheano, se poderá fazer uma história da verdade" ${ }^{11}$.

\section{Nota final}

Logicamente, este abandono da vontade de verdade como busca do absoluto ocasiona uma certa desordem na tradição do conhecimento científico. O motivo por que assim acontece é pelo fato de essa mutação implicar, também, uma mutação ao nível da própria temporalidade. E, com a atual mutação ao nível do lugar da experiência, hoje "acelerada" de modo irreversível, é possível falar, se não de uma "epistemologia da incerteza" (a validade das leis científicas teria forte caráter de reversibilidade), pelo menos de uma convicção segundo a qual, em vez de verdades universais e imutáveis, estamos diante de interpretações e narrativas.

\section{Referências}

11 FOUCAULT, Michel. A Verdade e as Formas. Jurídicas. Rio de Janeiro: Ed. Nau, 1999, p. $27 ; 142$. 
FOUCAULT, Michel. A Verdade e as Formas. Juridicas. Rio de Janeiro: Ed. Nau, 1999,

LÉVI-STRAUSS, Claude. O Pensamento Selvagem. Campinas: Papirus, 1989.

PAZ, Octavio. Claude Lévi-Strauss, on o Novo Festim de Esopo. São Paulo: Perspectiva, 1977

PECKER, Jean-Claude.. IN: Ideias Contemporâneas (Entrevistas do Le Monde). São Paulo: Ática, 1984.

POPPER, Karl, R. Um Mundo De Propensões. Lisboa: Fragmentos, 1991

WEBER, Max. O cientista e o politico. 3 ed. Lisboa Presença, 1979

WEFFORD, Francisco (Org.). Os clássicos da política. São Paulo, Ática, 1991. 